\title{
Urodynamic Detrusor Overactivity in Patients with Overactive Bladder Symptoms
}

\author{
Mohammed A. Al-Ghazo, Ibrahim Fathi Ghalayini, Rami Al-Azab, Osama Bani Hani, Yousef S. Matani, Yazan Haddad ${ }^{1}$ \\ Division of Urology, Department of General Surgery, King Abdullah University Hospital, Jordan University of Science and Technology Faculty of Medicine, Irbid; \\ ${ }^{1}$ Princess Haya Biotechnology Center, Jordan University of Science and Technology, Irbid, Jordan
}

\begin{abstract}
Purpose: To evaluate the relationship between urodynamic detrusor overactivity (DO) and overactive bladder (OAB) symptoms in men and women.

Methods: We reviewed the records of adult males and females who attended a tertiary referral center for urodynamic evaluation of $\mathrm{OAB}$ syndrome symptoms with the presence or absence of $\mathrm{DO}$. $\mathrm{DO}$ was calculated for symptoms alone or in combination. Results: The overall incidence of DO was $76.1 \%$ and $58.7 \%$ in male and female OAB patients, respectively. Of men $63 \%$ and $61 \%$ of women with urgency (OAB dry) had DO, while $93 \%$ of men and $69.8 \%$ of women with urgency and urgency urinary incontinence (OAB wet) had DO. Of women, $58 \%$ who were OAB wet had stress urinary incontinence symptoms with $26.4 \%$ having urodynamic stress incontinence. $6 \%$ of men and $6.5 \%$ of women with $\mathrm{OAB}$ symptoms had urodynamic diagnosis of voiding difficulties with postvoid residual greater than $100 \mathrm{~mL}$. Combination of symptoms is more accurate in predicting DO in OAB patients. The multivariate disease model for males included urge urinary incontinence (UUI) and urgency while for females it included UUI and nocturia.

Conclusions: There was a better correlation in results between $\mathrm{OAB}$ symptoms and the urodynamic diagnosis of $\mathrm{DO}$ in men than in women, more so in $\mathrm{OAB}$ wet than in $\mathrm{OAB}$ dry. Combination of symptoms of the $\mathrm{OAB}$ syndrome seems to have a better correlation with objective parameters from the bladder diary, filling cystometry, and with the occurrence of DO.
\end{abstract}

Keywords: Overactive bladder; Urodynamic investigation; Urinary incontinence; Detrusor overactivity

\section{INTRODUCTION}

According to the latest International Continence Society (ICS) recommendation, the overactive bladder $(\mathrm{OAB})$ syndrome is described as the presence of urgency, with or without urge urinary incontinence (UUI), usually with frequency and nocturia if there is no proven infection or other obvious pathological condition [1]. The implication of this definition is that the term $\mathrm{OAB}$ denotes a syndrome whose etiology is unknown. Generally speaking, detrusor overactivity (DO) is supposed to be a major underlying pathophysiology of $\mathrm{OAB}$. OAB is a symptomatic diagnosis, while $\mathrm{DO}$ is an urodynamic observation defined by involuntary detrusor contractions during the filling phase, which may be spontaneous or provoked [1].

Although there is consensus about the presence of these symptoms it is unclear how they are related, both individually as well as in combination, with objective parameters. Although improvement of symptoms is the principal goal of treatment, concurrent improvement in objective parameters will support the effectiveness of the intervention used. Some authors have suggested recently that patients with this symptom complex can be safely treated on the basis of their history, without the need for invasive urodynamics (UDS) tests. But whether it is an accurate method of diagnosis is not known. Several studies have
Corresponding author: Mohammed A. Al-Ghazo

Division of Urology, Department of General Surgery, King Abdullah University Hospital, Jordan University of Science and Technology Faculty of Medicine, 22110 Irbid 3030, Jordan

Tel: +962-2-7200600 / Fax: +962-2-7200621 / E-mail: alghazo@just.edu.jo

Submitted: January 4, 2011 / Accepted after revision: March 20, 2011
This is an Open Access article distributed under the terms of the Creative Commons Attribution Non-Commercial License (http://creativecommons.org/licenses/by-nc/3.0/) which permits unrestricted non-commercial use, distribution, and reproduction in any medium, provided the original work is properly cited. 
demonstrated that urinary symptoms do not accurately diagnose the underlying pathology compared with UDS $[2,3]$. The bladder has been described as an unreliable witness [4].

Most of the previous studies included either male or female patients but not both male and female patients. According to the new definition $\mathrm{OAB}$ symptoms are suggestive of DO, although the definition does not specify the actual correlation between $\mathrm{OAB}$ and $\mathrm{DO}$. We defined how well OAB symptoms, both individually as well as in combination, predict urodynamic $\mathrm{DO}$ using the new definitions of $\mathrm{OAB}$ and $\mathrm{OAB}$ symptoms in men and women from the same population group.

\section{MATERIALS AND METHODS}

This was a retrospective study of men and women (aged $\geq 18$ years) with symptoms of an overactive bladder (urinary frequency, urgency, nocturia, and/or UUI) referred to our urodynamic unit for further evaluation, between February 2002 and February 2007. All UDS were done at a specialist referral center performing about 10 to 15 UDS tests weekly in male and female children and adults who undergo standard UDS. We reviewed urodynamic report sheets and evaluated patients' age, voiding frequency ( $\geq$ eight voids per day), nocturia ( $\geq$ two voids per night), urgency and symptomatic incontinence (OAB dry or $\mathrm{OAB}$ wet, respectively), first sensation, maximum cystometric capacity (MCC), bladder compliance, and the presence or absence of DO. Those with neurological, vesical, bladder outlet and pelvic floor diseases or surgery were excluded.

Patients with frequency alone or nocturia alone were not considered to have OAB. Patient traces were examined to see if DO was present. Detrusor overactivity was defined as the occurrence of an involuntary detrusor contraction during filling phase, either spontaneous or provoked [1].

Those on antimuscarinics are instructed to stop ingesting them 1 week prior to attending for the test, thus, providing a washout period and avoiding any interference with test results. All UDS information, including patient demographics, medical history, examination, voiding diary, urinalysis, urine free flow rate, post-void residual volume, results of the filling and voiding phases, and bladder capacity, are entered during the test. All UDS investigations were done according to the ICS good urodynamics practices protocol [5]. Conventional filling cystometry was performed with patients in the supine position. The bladder was filled at a constant rate of $25 \mathrm{~mL}$ per minute using normal saline solution at room temperature for standard UDS.
After patients denoted MCC, a series of provocative maneuvers were undertaken by coughing 10 times with maximal effort in supine and sitting positions.

The results were statistically evaluated using Mann-Whitney and Fisher's exact probability tests for comparison of the findings between $\mathrm{DO}$ and no DO patients, and for comparison between symptoms and UDS findings. Fisher's exact probability test was performed to assess the association between symptoms and DO. A binary logistic regression modeling selection process was done with $\mathrm{DO}$ as the dependent variable and the potential risk factors including symptoms as possible predictor variables. P-values less than 0.05 were considered statistically significant. All data were analyzed using the Statistical Package for the Social Sciences program (SPSS ver. 16.0, SPSS Inc., Chicago, IL, USA).

\section{RESULTS}

Our study enrolled 209 non-neurogenic patients adult patients (117 men and 92 women) referred to our unit because they had complete persistent storage symptoms data entries available in the database of frequency, nocturia, urgency and/or UUI. They were evaluated by a urologic specialist prior to urodynamics. The overall incidence of DO was $76.1 \%$ (89 patients) and $58.7 \%$ (54 patients) in male and female OAB patients, respectively. Ten male DO patients and nine female DO patients revealed DO after provocative maneuvers, such as posture change or coughing. Compared with no DO patients, DO patients revealed significantly lower urodynamic parameters in both sexes (Table 1).

In male, 40 of 89 (44.9\%) of male DO patients were OAB wet and 3 of 28 no DO (10.7\%) were also OAB wet. In female patients, 37 of $54 \mathrm{DO}$ patients (68.5\%) were OAB wet, whereas 16 of 38 no DO patients (42.1\%) were also OAB wet. Also, $63 \%$ of men and $61.3 \%$ of women with urgency (OAB dry) had DO, while $93 \%$ of men and $69.8 \%$ of women with urgency and UUI (OAB wet) had DO. However, 58\% of women who were OAB wet had stress urinary incontinence (SUI) symptoms with 26.4\% having urodynamic stress incontinence.

The associations between the reported symptoms and UDS findings are presented in Table 2. In men, the urgency and incontinence symptoms were significantly associated with the presence of DO with lower micturition and bladder sensation volumes. In women, only incontinence was significantly associated with DO with a significant effect on all urodynamic parameters examined. However, there is a significant effect of 
Table 1. Comparison between DO patients and no DO patients in both sexes

\begin{tabular}{|c|c|c|c|c|c|}
\hline & Age (yr) & $\operatorname{MCC}(\mathrm{mL})$ & $\mathrm{FS}(\mathrm{mL})$ & $\mathrm{COMP}\left(\mathrm{mL} / \mathrm{cm} \mathrm{H}_{2} \mathrm{O}\right)$ & OAB wet \\
\hline \multicolumn{6}{|l|}{ Men } \\
\hline $\mathrm{DO}(\mathrm{n}=89)$ & $50.8 \pm 17.6$ & $271 \pm 61.5$ & $117.4 \pm 19.3$ & $24.7 \pm 4.0$ & $40(44.9)$ \\
\hline No DO $(\mathrm{n}=28)$ & $53.7 \pm 14.0$ & $337.1 \pm 50.8$ & $141.8 \pm 21.4$ & $32.1 \pm 6.2$ & $3(10.7)$ \\
\hline $\mathrm{P}$-value & 0.4 & $<0.001$ & $<0.001$ & $<0.001$ & 0.001 \\
\hline \multicolumn{6}{|l|}{ Women } \\
\hline $\mathrm{DO}(\mathrm{n}=54)$ & $46.4 \pm 14.8$ & $280.0 \pm 27.4$ & $105.4 \pm 11.7$ & $51.2 \pm 4.1$ & $37(68.5)$ \\
\hline No DO $(n=38)$ & $45.6 \pm 12.8$ & $347.9 \pm 29.0$ & $132.4 \pm 12.2$ & $60.0 \pm 4.0$ & $16(42.1)$ \\
\hline $\mathrm{P}$-value & 0.8 & $<0.001$ & $<0.001$ & $<0.001$ & 0.01 \\
\hline
\end{tabular}

Values are presented as mean $\pm \mathrm{SD}$ or number $(\%)$.

DO, patients with detrusor overactivity; no DO, patients without detrusor overactivity; MCC, maximum cystometric capacity; FS, first sensation; COMP, bladder compliance; $\mathrm{OAB}$, overactive bladder.

Table 2. Association of overactive bladder symptoms and urodynamics findings in men and women

\begin{tabular}{|c|c|c|c|c|c|c|}
\hline & \multicolumn{3}{|c|}{ Men } & \multicolumn{3}{|c|}{ Women } \\
\hline & $\operatorname{MCC}(\mathrm{mL})$ & $\mathrm{FS}(\mathrm{mL})$ & $\mathrm{COMP}\left(\mathrm{mL} / \mathrm{cm} \mathrm{H}_{2} \mathrm{O}\right)$ & $\operatorname{MCC}(\mathrm{mL})$ & $\mathrm{FS}(\mathrm{mL})$ & $\mathrm{COMP}\left(\mathrm{mL} / \mathrm{cm} \mathrm{H}_{2} \mathrm{O}\right)$ \\
\hline \multicolumn{7}{|l|}{ Frequency } \\
\hline Yes & 284.8 & 121.7 & 26.7 & 306.8 & 115.1 & 54.8 \\
\hline No & 293.3 & 127.7 & 25.7 & 309.5 & 118.2 & 54.9 \\
\hline P-value & 0.6 & 0.4 & 0.4 & 0.9 & 0.5 & 0.9 \\
\hline \multicolumn{7}{|l|}{ Nocturia } \\
\hline Yes & 281.6 & 122.2 & 26.0 & 304.3 & 114.6 & 53.7 \\
\hline No & 301.3 & 125.9 & 27.6 & 314.4 & 119.9 & 56.9 \\
\hline P-value & 0.2 & 0.4 & 0.1 & 0.3 & 0.2 & $0.03^{\text {a) }}$ \\
\hline \multicolumn{7}{|l|}{ Urgency } \\
\hline Yes & 272.0 & 120.3 & 25.4 & 305.3 & 115.2 & 54.3 \\
\hline No & 316.9 & 129.2 & 28.6 & 320.0 & 122.4 & 57.2 \\
\hline P-value & $<0.001^{\mathrm{b})}$ & $0.02^{\text {a) }}$ & $0.02^{\text {a) }}$ & 0.2 & 0.1 & 0.06 \\
\hline \multicolumn{7}{|l|}{ UUI } \\
\hline Yes & 265.0 & 116.8 & 23.9 & 296.9 & 112.6 & 53.3 \\
\hline No & 217.5 & 132.2 & 29.9 & 334.8 & 125.9 & 58.6 \\
\hline P-value & $<0.001^{\mathrm{b})}$ & $<0.001^{\text {b) }}$ & $<0.001^{\mathrm{b})}$ & $<0.001^{\text {b) }}$ & $0.001^{b)}$ & $<0.001^{\mathrm{b})}$ \\
\hline
\end{tabular}

UUI, urge urinary incontinence; MCC, maximum cystometric capacity; FS, first sensation; COMP, bladder compliance.

${ }^{\text {a) }} \mathrm{P}<0.05 .{ }^{\text {b) }} \mathrm{P}<0.001$.

nocturia on badder compliance while the other parameters did not change significantly. We further analyzed these retrospective data to find out if clinicians could better predict DO when some clinical factors were present. As shown in Table 3, analysis of OAB symptoms and DO were studied in male and female subjects, separately. Of the four symptoms only incontinence was associated significantly with DO in male patients. In female patients, nocturia and incontinence were significantly associat- ed with DO. Univariate logistic regression showed that the highest odds ratios (OR) of DO were for UUI in men (4.2) and women (2.8) (Table 4). In both sexes, age was not significantly involved in the risk of DO. When symptoms were studied separately, the frequency and urgency were not significantly involved in risk of DO in both sexes. However, analysis of interactions showed that they played a role in slightly increasing the risk of other factors. The interaction of frequency and urgency was 
Table 3. Association of detrusor overactivity and selected factors

\begin{tabular}{lcccc}
\hline & \multicolumn{2}{c}{ Men } & \multicolumn{2}{c}{ Women } \\
\cline { 2 - 3 } \cline { 5 - 5 } Age & DO & P-value & DO & P-value \\
$\geq 50$ & $42(47.2)$ & 0.2 & $21(38.9)$ & 0.5 \\
$<50$ & $17(60.7)$ & & $16(42.1)$ & \\
Frequency & & & & 0.3 \\
Yes & $67(75.3)$ & 0.4 & $31(57.4)$ & \\
No & $20(71.4)$ & & $19(50.0)$ & \\
Nocturia & & & & $0.03^{\text {a) }}$ \\
Yes & $67(75.3)$ & 0.2 & $39(72.2)$ & \\
No & $18(64.3)$ & & $19(50.0)$ & \\
Urgency & & & & 0.2 \\
Yes & $63(70.8)$ & 0.07 & $46(85.2)$ & \\
No & $15(53.6)$ & & $29(76.3)$ & \\
UUI & & & & \\
Yes & $59(66.3)$ & $0.001^{\mathrm{b})}$ & $43(79.6)$ & \\
No & $9(32.1)$ & & $22(57.9)$ & \\
\hline
\end{tabular}

Values are presented as number (\%).

UUI, urge urinary incontinence; DO, detrusor overactivity.

${ }^{a)} \mathrm{P}<0.05 .{ }^{\text {b) }} \mathrm{P}<0.001$. significant in men $(\mathrm{P}=0.04)$ but not in women $(\mathrm{P}=0.1)$.

As for binary interactions in men, the most noticeable was the urgency and incontinence $(\mathrm{P}=0.003)$. The $\mathrm{OR}$ of incontinence increased from 4.2 to 6.8 by the addition of the urgency (thus neglecting the cases with urgency alone). Further, the results show nearly a doubling in OR when any of the other factors is added to these two. Adding either nocturia or frequency increased the OR to $12.4(\mathrm{P}=0.02)$.

In women, the situation is different. Since univariate risks of nocturia and incontinence were significant, further interactions showed more significant risks, namely the interactions of nocturia with either frequency $(\mathrm{P}=0.005)$ or incontinence $(\mathrm{P}=0.008)$. Although incontinence had the highest OR in univariate analysis, the interactions showed that frequency and nocturia were the major risk players in women. Adding either incontinence or urgency to these two factors increased the OR to $11.5(\mathrm{P}=0.002)$.

Multivariate logistic regression was used for prediction of the direct risk factors involved in the disease model. The OR in a multivariate model represents the exponential factor for each variable in a one equation (Table 5). The disease model for males included UUI and urgency while for females it included UUI and nocturia. So far, the results of multivariate analysis were

Table 4. Univariate binary logistic regression analysis for odds ratios of detrusor overactivity

\begin{tabular}{|c|c|c|c|c|c|c|c|}
\hline \multirow{2}{*}{ Factors } & & \multicolumn{3}{|c|}{ Men } & \multicolumn{3}{|c|}{ Women } \\
\hline & & OR & $95 \% \mathrm{CI}$ & $\mathrm{P}$-value & OR & $95 \% \mathrm{CI}$ & P-value \\
\hline \multirow[t]{5}{*}{ Univariate } & Age $(\geq 50)$ & 0.5 & $0.2-1.4$ & 0.2 & 0.9 & $0.4-2.0$ & 0.8 \\
\hline & Frequency & 1.2 & $0.5-3.2$ & 0.7 & 1.3 & $0.6-3.1$ & 0.5 \\
\hline & Nocturia & 1.7 & $0.7-4.2$ & 0.3 & 2.6 & $1.1-6.2$ & $0.03^{\text {a) }}$ \\
\hline & Urgency & 2.1 & $0.9-5.0$ & 0.1 & 1.8 & $0.6-5.1$ & 0.3 \\
\hline & UUI & 4.2 & $1.7-10.3$ & $0.002^{\mathrm{a})}$ & 2.8 & $1.1-7.2$ & $0.03^{\text {a) }}$ \\
\hline \multirow[t]{10}{*}{ Interactions } & Fr $\times$ Nocturia & 1.4 & $0.6-3.2$ & 0.5 & 4.1 & $1.5-10.9$ & $0.005^{\mathrm{a})}$ \\
\hline & Fr $\times$ Urgency & 2.6 & $1.1-6.3$ & $0.04^{\text {a) }}$ & 2.0 & $0.8-4.8$ & 0.1 \\
\hline & Fr $\times$ UUI & 3.0 & $1.1-8.1$ & $0.03^{\text {a) }}$ & 3.3 & $1.2-8.8$ & $0.02^{\mathrm{a})}$ \\
\hline & Nocturia $\times$ Urgency & 3.2 & $1.2-8.3$ & $0.02^{\text {a) }}$ & 3.2 & $1.3-7.5$ & $0.01^{\text {a) }}$ \\
\hline & Nocturia $\times$ UUI & 3.3 & $1.2-8.9$ & $0.02^{\text {a) }}$ & 3.3 & $1.4-8.0$ & $0.008^{\text {a) }}$ \\
\hline & Urgency $\times$ UUI & 6.8 & $1.9-24.2$ & $0.003^{\mathrm{a})}$ & 3.0 & $1.3-7.1$ & $0.01^{\text {a) }}$ \\
\hline & Fr $\times$ Nocturia $\times$ UUI & 1.9 & $0.7-5.5$ & 0.2 & 11.5 & $2.5-52.7$ & $0.002^{\mathrm{a})}$ \\
\hline & Fr $\times$ Nocturia $\times$ Urgency & 3.7 & $1.2-11.6$ & $0.02^{\text {a) }}$ & 11.5 & $2.5-52.7$ & $0.002^{\text {a) }}$ \\
\hline & Nocturia x UUI $\times$ Urgency & 12.4 & $1.6-95.8$ & $0.02^{\text {a) }}$ & 4.1 & $1.5-10.9$ & $0.005^{\text {a) }}$ \\
\hline & Fr $\times$ Urgency $\times$ UUI & 12.4 & $1.6-95.8$ & $0.02^{\text {a) }}$ & 6.9 & $1.9-25.2$ & $0.004^{\mathrm{a})}$ \\
\hline
\end{tabular}

UUI, urge urinary incontinence; Fr, frequency; OR, odds ratio; CI, confidential interval.

${ }^{\text {a) }} \mathrm{P}<0.05$. 
Table 5. Multivariate binary logistic regression analysis for odds ratios of detrusor overactivity in both sexes

\begin{tabular}{llll}
\hline Factors & OR & $95 \%$ CI & P-value \\
\hline Men & & & \\
Urgency & 2.7 & $1.0-7.0$ & $0.04^{\text {a) }}$ \\
UUI & 4.8 & $1.9-12.5$ & $0.001^{\text {a) }}$ \\
Women & & & \\
Nocturia & 2.6 & $1.1-6.4$ & $0.04^{\text {a) }}$ \\
UUI & 2.9 & $1.1-7.4$ & $0.03^{\text {a) }}$ \\
\hline
\end{tabular}

UUI, urge urinary incontinence; Fr, frequency; OR, odds ratio; CI, confidential interval.

${ }^{\text {a) }} \mathrm{P}<0.05$.

consistent with the binary interactions. However, in the case of women, the frequency was neglected from the model for simple reason of insignificant univariate result, which is a rule for multivariate model prediction.

\section{DISCUSSION}

In the latest recommendation, the ICS had updated the definition for $\mathrm{OAB}$ syndrome into urgency, with or without urge incontinence, usually with frequency and nocturia [1]. The main symptom of this definition is the urgency symptom, but it is unclear what this is based on. Although according to the ICS definition, urodynamic study is not required routinely to make a diagnosis of $\mathrm{OAB}$, some physicians are concerned that a correct diagnosis will be missed in many patients, and they will not receive appropriate treatment because the bladder has been described as an unreliable witness [6].

Sekido et al. [7] retrospectively evaluated 50 patients (12 males and 38 females) with OAB symptoms in regard to urodynamic parameters and the presence or absence of DO. The overall incidence of DO was $75 \%$ and $36.8 \%$ in male and female patients, respectively. They concluded that, in contrast to male OAB, DO might not be a major underlying cause of uncomplicated female $\mathrm{OAB}$. Therefore, the prevalence of $\mathrm{DO}$ in $\mathrm{OAB}$ females may depend on the population studied, the definition of this condition and the methods used.

Each symptom of frequency, nocturia, urgency and incontinence was associated with lower micturition and sensation volumes on filling cystometry. This association was not significant except for each of urgency and incontinence in men and incontinence alone in women. Of the four symptoms that are currently considered to be part of the $\mathrm{OAB}$ syndrome, the incontinence symptom is the best associated with objective parameters from the bladder diary, filling cystometry, and with the occurrence of DO in both sexes. Although urgency is associated with a significant effect on all urodynamic parameters examined in men, there is no significant effect on the occurrence of DO (Tables 2, 3 ). We agree with the others that there is a need for a validated urgency scale that measures urgency rather than bladder sensation $[8,9]$. In univariate analysis, when symptoms studied separately, the frequency and urgency were not significantly involved in risk of DO in both sexes while interactions showed that both slightly increase the risk of other factors. The interaction of these was significant in men but not in women (Table 4). This is supportive to our belief that $\mathrm{OAB}$ symptoms may have different pathophysiology in both sexes. We believe clinicians could better predict DO when some clinical factors were combined together and not by depending on a single symptom. This is obvious from the binary interactions of OAB symptoms such as urgency and incontinence. Incontinence is usually associated with urgency, so this can explain the increase in OR of incontinence from 4.2 to 6.8 by the addition of the urgency in men. Furthermore, the results show nearly a doubling in OR when any of the other symptoms is added to these two symptoms.

In women univariate risks of nocturia and incontinence were significant and further interactions showed more significant risks, namely the interactions of nocturia with either frequency or incontinence. Although incontinence had the highest OR in univariate analysis, the interactions showed that frequency and nocturia were the major risk factors in women in contrast to men. The frequency is univariately weakly predictive of DO but not significant in a multivariate model with urgency, incontinence and nocturia. This is similar to the findings of other authors demonstrated by a self reported mail questionnaire in women [10]. Also, Hashim and Abrams [8] showed in their study that increasing voiding frequency did not have any effect on increasing the accuracy of diagnosis of DO except in women with 10 or more daytime micturition episodes. However, we cannot ignore the role of frequency in predicting DO especially when combined with other symptoms. Van Brummen et al. [11] investigated the association between overactive bladder symptoms in women and objective parameters from the bladder diary and conventional filling cystometry. The frequency symptom as well as the UUI symptom was significantly associated with the presence of DO. They considered the frequency symptom as being obligatory for considering one to have an $\mathrm{OAB}$. The weakness in their study and our study is that analysis 
was not done to assess whether increasing frequency made a difference to the diagnostic value and association between $\mathrm{OAB}$ and DO, using different cutoff points for frequency.

Urgency in men was associated with DO in multivariate analysis, but not in univariate analysis. Some authors stated the frequency symptom, not the urgency symptom, is best associated with them in females who underwent UDS [11]. Conversely, frequency alone was reported to be a poor predictor of DO (31.4\%) in female OAB patients, and having urgency, frequency and UUI had the highest sensitivity in predicting DO $(61.0 \%)$ in females. In our study, $62 \%$ of women with frequency alone have DO, while $87 \%$ with combined urgency, frequency and UUI have DO. This confirms the need for a validated urgency scale that measures urgency more accurately.

This study adds to the body of evidence that questions the validity of using invasive urodynamic procedures before initiating treatment for the debilitating symptoms of an OAB. Indeed, the results of a randomized, double-blind clinical trial in which patients were enrolled and treated on the basis of symptoms alone support this management strategy [12]. This approach would encourage more physicians to explore these problems with their patients, reserving referral for costly urodynamics for those patients who fail to respond to first-line therapy. This management strategy may be suitable for our people with limited income to pay for the tests. For this reason, UDS should be done only if it is going to change patient treatment or help differentiate the etiology of voiding dysfunction, or if it is done after failed conservative/medical treatment [13]. If standard UDS fails to reproduce symptoms, referral for ambulatory UDS may be considered when available. The absence of DO during an artificial bladder test even with provocative maneuvers is not an absolute confirmation of lack of DO in "real life" situations.

The present study had several limitations. First, the study was retrospective. Second, our study population was a selected group of patients with complaints that were candidate for urodynamic investigation. Therefore, they represent patients with bothersome symptoms. To what extent our results can be generalized to the population remains unanswered. Third, the study compares subjective symptoms with objective parameters. The bladder is a bad witness, and the symptoms of frequency, nocturia, and urgency may arise because of hypersensitivity of the bladder stretch but also may occur when the bladder contracts inappropriately due to DO. Fourth, the follow-up data were lacking in some patients because some in the present study were referred to our urology unit purely for management for a short duration. Therefore, there was not adequate information regarding whether or not urodynamic findings altered management for these patients. Continuing arguments against 'no need for UDS in OAB patients' might prove fruitless. Rather, we need knowledge and/or evidence-based guidelines that define the $\mathrm{OAB}$ patients in whom UDS could confer a benefit.

In conclusion, the definition of OAB based on urgency is a better predictor in men than in women. When symptoms were used together, only urgency and UUI in men and nocturia and UUI in women significantly increased the prediction of DO. It is important to inquire about the reproduction of symptoms during UDS and correlate this with findings during the test. There is a need for a validated urgency scale that measures urgency rather than bladder sensation. The pathophysiology of female OAB might be different from that of male OAB. Therefore, treatment outcomes must be evaluated for males and females, separately. Further prospective studies are needed to provide more information about the precise role of urodynamics for men and women with $\mathrm{OAB}$ symptoms.

\section{CONFLICT OF INTEREST}

No potential conflict of interest relevant to this article was reported.

\section{REFERENCES}

1. Abrams P, Cardozo L, Fall M, Griffiths D, Rosier P, Ulmsten U, et al. The standardisation of terminology of lower urinary tract function: report from the Standardisation Sub-committee of the International Continence Society. Neurourol Urodyn 2002;21:167-78.

2. Jarvis GJ, Hall S, Stamp S, Millar DR, Johnson A. An assessment of urodynamic examination in incontinent women. Br J Obstet Gynaecol 1980;87:893-6.

3. Cundiff GW, Harris RL, Coates KW, Bump RC. Clinical predictors of urinary incontinence in women. Am J Obstet Gynecol 1997;177: 262-6.

4. Blaivas JG. The bladder is an unreliable witness. Neurourol Urodyn 1996;15:443-5.

5. Schäfer W, Abrams P, Liao L, Mattiasson A, Pesce F, Spangberg A, et al. Good urodynamic practices: uroflowmetry, filling cystometry, and pressure-flow studies. Neurourol Urodyn 2002;21:261-74.

6. Flisser AJ, Blaivas JG. Role of cystometry in evaluating patients with overactive bladder. Urology 2002;60(5 Suppl 1):33-42.

7. Sekido N, Hinotsu S, Kawai K, Shimazui T, Akaza H. How many 
uncomplicated male and female overactive bladder patients reveal detrusor overactivity during urodynamic study? Int J Urol 2006; 13:1276-9.

8. Hashim $\mathrm{H}$, Abrams P. Is the bladder a reliable witness for predicting detrusor overactivity? J Urol 2006;175:191-4.

9. Chapple CR, Artibani W, Cardozo LD, Castro-Diaz D, Craggs M, Haab F, et al. The role of urinary urgency and its measurement in the overactive bladder symptom syndrome: current concepts and future prospects. BJU Int 2005;95:335-40.

10. Matharu G, Donaldson MM, McGrother CW, Matthews RJ. Relationship between urinary symptoms reported in a postal questionnaire and urodynamic diagnosis. Neurourol Urodyn 2005;24:100-5.
11. van Brummen HJ, Heintz AP, van der Vaart CH. The association between overactive bladder symptoms and objective parameters from bladder diary and filling cystometry. Neurourol Urodyn 2004; 23:38-42.

12. Van Kerrebroeck P, Kreder K, Jonas U, Zinner N, Wein A; Tolterodine Study Group. Tolterodine once-daily: superior efficacy and tolerability in the treatment of the overactive bladder. Urology 2001; 57:414-21.

13. Colli E, Artibani W, Goka J, Parazzini F, Wein AJ. Are urodynamic tests useful tools for the initial conservative management of nonneurogenic urinary incontinence? A review of the literature. Eur Urol 2003;43:63-9. 